\title{
Fracture resistance of premolars with bonded amalgam restorations
}

\begin{abstract}
Abdul-Haq A Suleiman
BDS, MS, PhD (Prof)
\end{abstract}

Mohammad Gh Hamdoon BDS, MSc (Assist Lect)
Department of Conservative Dentistry

College of Dentistry, University of Mosul

\begin{abstract}
The aim of this in vitro study is to evaluate the fracture resistance of premolars with three surface amalgam restorations. Fifty premolars were used, and divided into five groups. The teeth in group one remains intact whereas the teeth in the second group prepared and not restored. The teeth in the third group prepared and restored with amalgam only. In groups four and five, the amalgam restorations were lined with All-Bond 2 and Scotchbond Multi Purpose Plus respectively. After thermocycling, the teeth were tested under universal compression machine at a crosshead speed $5 \mathrm{~mm} /$ minute. Data were analyzed using one way Analysis of Variance and Duncan's Multiple Range Test. The results of this study indicates that both Scotchbond Multi Purpose Plus and All-Bond 2 increase the fracture resistance as compared to the control groups (groups two and three). The results of this study also show no significant difference between the two bonding agents regarding teeth fracture resistance.
\end{abstract}

Key Words: Fracture resistance, bonded amalgam.

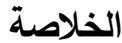

$$
\begin{aligned}
& \text { الغرض من هذه الدراسة خارج الجسم هو لتقييم }
\end{aligned}
$$

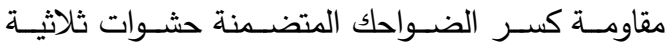

$$
\begin{aligned}
& \text { الأسطح. تم استخدام خمسين ضاحك مقسمة إلى خمسة } \\
& \text { مجاميع متساوية. تُركت أسنان المجموعة الأولى سليمة } \\
& \text { بدون تحضير بينما تم تحضير أسنان المجموعة الثانية }
\end{aligned}
$$

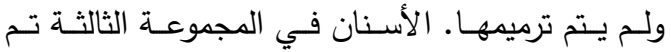

$$
\begin{aligned}
& \text { ترميمها بحشـوة الأملغـم فقط. أمـا أسـنان المجمـوعتين }
\end{aligned}
$$

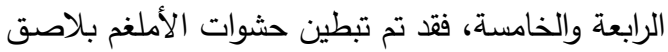

Scotchbond Multi ) ولاصق (All-Bond 2) Purpose Plus الحراري، تم فحص الأسنان تحت آلة الكبس القياسية وبسرعة ه ملم/ دقيقة. تم تحليل البيانات باختبار تحليل

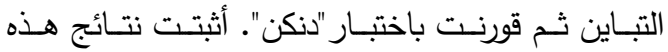
الدراسة انه كلا من اللواصق المستخدمة سوف يزيد من

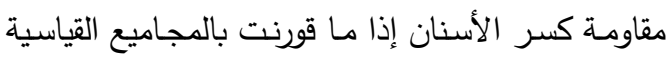

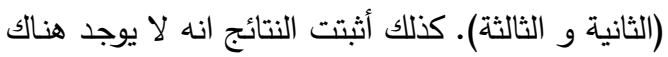

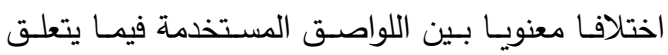

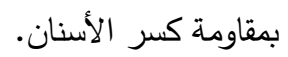

\section{INTRODUCTION}

Silver amalgam used in dentistry since $1826,{ }^{(1)}$ and still frequently used to restore proximo-occlusal cavities in posterior teeth due to its easy handling characteristic and obtaining of appropriate proximal contact. ${ }^{(2)}$

Amalgam can not reinforce weak walls because of its low resilience and high modulus of elasticity. Therefore, it is necessary to remove the enamel with no support of dentin in large cavities in order to reduce the possibility of cusp fracture that compromise the tooth. ${ }^{(3-5)}$

Adhesive resins can be used as cavity liners with silver amalgam to increase the 


\section{Suleiman AA, Hamdoon MGh}

retention and to reduce microleakage. ${ }^{(1,6)}$ The ability of the adhe-sive resins to bond with the tooth structure and amalgam alloy could increase the frac-ture resistance of teeth. ${ }^{(3,7,10)}$

The aim of this study is to evaluate the effect of bonding agents on the fracture resistance of maxillary premolars with mesio-occluso-distal amalgam restorations.

\section{MATERIALS AND METHODS}

Fifty, non carious, sound human permanent upper premolars were stored in $0.01 \%$ thymol and refrigerated until used for cavity preparation and restoration. ${ }^{(11)}$

The selected teeth have $9.0-10.0 \mathrm{~mm}$ bucco-lingual width measured from the greatest convexity of both buccal and lingual surfaces with mean width $9.53 \pm 0.28$ $\mathrm{mm}$. Teeth were cleaned by hand scaler and polished with non fluoridated pumice. Any tooth with crack was exlucuded.

The tooth mounted in $2 \times 2 \mathrm{~cm}$ plastic ring so that the roots of the teeth were embedded up to $2 \mathrm{~mm}$ below cementoenamel junction with cold cure acrylic resin.

Standardized mesio-occluso-distal (MOD) cavities were prepared with no. 245 carbide bur using high-speed handpiece with water coolant, one bur for each 5 cavities was used.

The high-speed handpiece was held by special holder in a manner that the long axis of the bur being perpendicular to the occlusal surface using a surveyor.

The carbide bur moves at fixed horizontal plane within a certain limited space using template that representing the occlusal view of the cavity design.

Only the neck of the bur was allowed to touch the template in order to keep the dimension of the template and the cavities as constant as possible. The cavity dimension was as follow: $1 \mathrm{~mm}$ occlusal isthmus, $2 \mathrm{~mm}$ occluso-pulpal height of occlusal portion, $4 \mathrm{~mm}$ height of the proximal box, $4 \mathrm{~mm}$ width of the proximal box and $1 \mathrm{~mm}$ mesio-distal depth of the gingival seat.

The teeth in group one remain intact, whereas teeth in group two prepared but not restored. Amalgam restorations Vivacap (Vivadent, Ets, FL-9494 Schaan / Liechtenstein) were placed in the remaining three groups. In group three, amalgam placed directly into the cavity. In group four, the amalgam was bonded with AllBond 2 bonding agent (Bisco, Inc. Schaumburg, Ill 60193, USA), while in group five the amalgam was bonded with Scotch-bond Multi Purpose Plus bonding agent (3M, St Paul MN 55144, USA). Both bonding agents were applied according to manufacturer's instruction.

The specimens were thermocycled for 300 cycles (temperature between 5-55 ${ }^{\circ} \mathrm{C}$ ) and stored for 1 day at $10{ }^{\circ} \mathrm{C}$ before being tested under compression. ${ }^{(12)}$

A universal compression machine (Soil Test Co, USA) was used for testing procedure. A 5-mm diameter crosshead with a speed of $5 \mathrm{~mm} / \mathrm{min}$ was used touching only the buccal and lingual cusps but not the restoration, until fracture occurred (Figure).

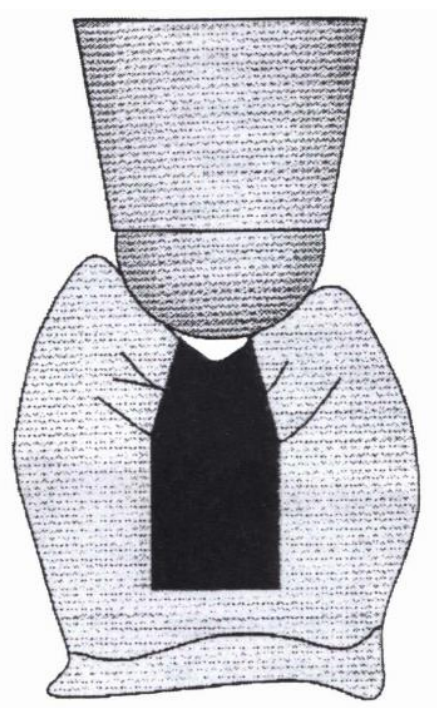

Figure: Testing rod touch buccal and lingual cusps

The data obtained in this study were analyzed using one way analysis of variance (ANOVA) test, at $p \leq 0.05$. Duncan's Multiple Range Test (DMRT) was performed to compare the significantly different groups. 


\section{RESULTS}

The results of this study showed that both groups that bonded with All-Bond 2 $(119.60 \pm 32.75 \mathrm{Kg})$ and Scotchbond Multi Purpose Plus $(130.60 \pm 43.96 \mathrm{Kg})$ significantly increase the fracture resistance of teeth over the groups restored with amalgam only $(70.90 \pm 6.88 \mathrm{Kg})$ and prepared only $(70.4 \pm 10.27 \mathrm{Kg})$. There was no significant difference between Sco- tchbond Multi Purpose Plus as compared to sound unprepared teeth $(150.50 \pm 12.42$ $\mathrm{Kg}$ ). Bonded groups are not statistically different. The minimum and maximum values for the load that required to produce cusp fracture were listed in Table (1). The data were analyzed using one way ANOVA (Table 2). DMRT was used to compare the significantly different groups (Table 3).

Table (1): Minimum and maximum load (Kg) that required to produce cusp fracture

\begin{tabular}{cccc}
\hline Group Treatment & No. & Minimum & Maximum \\
\hline Sound Unprepared & 10 & 120.00 & 163.20 \\
Prepared But Not Restored & 10 & 55.15 & 90.10 \\
Vivacap Amalgam & 10 & 60.25 & 85.15 \\
Vivacap Amalgam + AB2 & 10 & 69.20 & 194.15 \\
Vivacap Amalgam + SBMP & 10 & 80.40 & 227.50 \\
\hline
\end{tabular}

No. $=$ Number of specimens.

$\mathrm{AB} 2=$ All-Bond 2.

SBMP $=$ Scotchbond Multi Purpose Plus.

Table (2): Analysis of Variance for the effect of bonding agent on the fracture resistance of premolars

\begin{tabular}{ccccc}
\hline Source & df & SS & MS & F-value \\
\hline Between Groups & 4 & 52325.343 & 13081.336 & 19.595 \\
Within Groups & 45 & 30042.037 & 667.601 & \\
Total & 49 & 82367.380 & & \\
\hline
\end{tabular}

$\mathrm{df}=$ Degree of freedom.

$\mathrm{SS}=$ Sum of squares.

MS $=$ Mean square.

Table (3): Duncan Multiple Range Test for the effect of bonding agent on the fracture resistance of premolars

\begin{tabular}{cccc}
\hline Group Treatment & No. & Mean $(\mathbf{k g}) \pm$ SD & $\begin{array}{c}\text { Duncan } \\
\text { Grouping }\end{array}$ \\
\hline Sound unprepared & 10 & $150.50 \pm 12.42$ & $\mathrm{~A}$ \\
Prepared but not restored & 10 & $70.40 \pm 10.72$ & $\mathrm{C}$ \\
Vivacap amalgam & 10 & $70.90 \pm 6.88$ & $\mathrm{C}$ \\
Vivacap amalgam + AB2 & 10 & $119.60 \pm 32.75$ & $\mathrm{~B}$ \\
Vivacap amalgam + SBMP & 10 & $130.60 \pm 43.96$ & $\mathrm{AB}$ \\
\hline No. = Number of specimens. & & \\
SD: Standard deviation. & & \\
AB2 $=$ All-Bond 2. & & \\
SBMP = Scotchbond Multi Purpose Plus. & \\
Means with same letters are not significantly different. &
\end{tabular}




\section{DISCUSSION}

Ideally, a restorative material should strengthen the tooth and protect against further fracture. Bonding systems designed to bond amalgam to enamel and dentin have been introduced in an effort to compensate for some disadvantages presented by these restorations like the lack of adhesion properties and microleakage. ${ }^{(1)}$

The results of this study showed statistically significant differences between the amalgam bonded with Scotchbond Multi Purpose Plus and All-Bond 2 as compared to non bonded group and prepared only group, at the same time there was no differences between the two liners.

These results are in agreement with Mento et al., ${ }^{(14)}$ who revealed that the restorations that are lined with bonding agent (Scotchbond Multi Purpose Plus) exhibited an increase of the fracture resistance over the teeth with conventional rest-orations.

The use of Scotchbond Multi Purpose Plus and All-Bond 2 will regain the cusp fracture resistance to 0.86 and 0.79 , respectively. Such results suggest that using bonding agents associated with silver amalgam reduce cuspal fracture due to the binding capacity of bonding agent with tooth structure. The current results were also in agreement with Eakle et al. ${ }^{(12)}$ and Oliveira et al., ${ }^{(7)}$ who found that teeth restored with bonded amalgam were more resistant to fracture than teeth restored with amalgam only.

The results of this study disagree with Stamplia et $a l^{(15)}$ and Santos and Meiers, ${ }^{(16)}$ who stated that fracture resistance of bonded amalgam restorations was not differ from teeth restored with amalgam restorations without bonding, and this is due to the differences employed in the methodology and testing procedure.

The use of amalgam without liners will reduce the teeth strength to 0.47 , when compared to the sound unprepared group. At the same time the unrestored group (group two) showed a reduction in fracture resistance to 0.46 . These results consolidate the study that the use of bonding agents would increase the fracture resistance of cusps.

The modes of failure in the bonded restorations include fracture within tooth structure, complete cusp fracture, fracture within restoration and mixed failure (fracture within tooth structure, fracture at interface and /or fracture within restoration). The most common mode of failure was fracture within tooth structure $(60 \%$ in Scotchbond Multi Purpose Plus and 50\% All-Bond 2). This failure occurs when the bond strength exceed the cohesive strength of enamel and dentin due to the formation of hybrid layer and mechanical interlocking at the bonding-tooth interface.

\section{CONCLUSION}

It can be concluded that the use of Scotchbond Multi Purpose Plus and AllBond 2, with silver amalgam, will increase the fracture resistance of maxillary premolars with MOD restorations, and at the same time there was no statistical difference between Scotchbond Multi Purpose Plus and All-Bond 2 regarding fracture resistance.

The use of amalgam restorations without liner result in considerable compromization to the teeth structure strength approximated to that of prepared teeth without restoration. Therefore, it may be important for clinicians to evaluate the tooth condition, applying adhesive in the cavity preparation whenever the tooth presents considerable weakening.

\section{REFERENCES}

1- Staninec M, Holt M. Bonding of amalgam to tooth structure: Tensile adhesion and microleakage tests. J Prosthet Dent. 1988; 59: 397-402.

2- Gwinnett AJ, Baratieri LN, Monteiros J, Ritter AV. Adhesive restorations with amalgam: Guidelines for the clin-ician. Quintessence Int. 1994; 10: 687-695.

3- El-Sharif MH, Halhoul MN, Kamar AA, Nour El-Din A. Fracture strength of premolars with class 2 silver ama-lgam restorations. Oper Dent. 1988; 13: 50-53.

4- Olmez A, Ulusu T. Bond strength and clinical evaluation of new dentinal bonding agent to amalgam and resin composite. 
Quintessence Int. 1995; 26: 785793.

5- Ree GJ, Norling BK, Draheim RN. Fracture strength of molars containing three surface amalgam restorations. $J$ Prosthet Dent. 1982; 47: 185187.

6- Ben Amar A, Nordenberg D, Fischer J, Gorfil G. The control of marginal microleakage in amalgam restorations using a dentin adhesive: A pilot study. Dent Mater. 1987; 3: 9499.

7- $\quad$ Oliveira JP, Cochran MA, Moore BK. Influence of bonded amalgam rest-orations on the fracture strength of teeth. Oper Dent. 1996; 21: 110115.

8- Cotert HS, Sen BH, Balkman M. In vitro comparison of cuspal fracture resistance of posterior teeth restored with various adhesive restoration. Int $J$ Prosthodont. 2001; 14: 374-378.

9- Diaz de Sousa GM, Pereira GD, Dias CT, Paulillo L. Fracture resistance of teeth with bonded amalgam technique. Oper Dent. 2002; 26: 511-515.

10- Diaz de Sousa GM, Pereira GD, Dias CT, Paulillo L. Fracture resistance of premolars with bonded
Cl II amal-gams. Oper Dent. 2002; 27: 349-353.

11- Sheth J. Cuspal deformation and fra-cture resistance of teeth using dentin adhesive and composite resin. MS thesis. University of Iowa. USA. 1986.

12- Eakle W, Staninec M, Lacy A. Effect of bonded amalgam on the fracture resistance of teeth. $J$ Prosthet Dent. 1992; 68: 257-260.

13-Khers SC, Carpenter CW, Vetter JD, Staley RN. Anatomy of cusps of posterior teeth and their fracture pot-ential. $J$ Prosthet Dent. 1990; 64: 139147.

14- Minto AM, Dinell W, Nonaka T, Thome LH. Comparative study of the fracture resistance of sound upper premolars and upper premolars restored with bonded amalgam. Pesqui Odontol Bras. 2002; 16: 121-126.

15- Stamplia LL, Nicholls JI, Jones DW. Fracture resistance of teeth with resin-bonded restorations. J Prosthet Dent. 1986; 55: 694-698.

16- Santos AC, Meiers JC. Fracture resis-tance of premolars with MOD amal-gam restorations lined with amalgam bond. Oper Dent. 1994; 19: 2-6. 